\title{
Worldmaking, Legal Education, and the Saga Comic Book Series
}

\author{
Guilherme Vasconcelos Vilaça' ${ }^{1}$
}

Accepted: 13 September 2021 / Published online: 21 September 2021

(c) The Author(s), under exclusive licence to Springer Nature B.V. 2021, corrected publication 2021

\begin{abstract}
This article argues that to disrupt legal education in a radical sense, students need to become acquainted with the art of worldmaking and the view that law is a "way of worldmaking". First, I show that law is a cultural semiotic practice that requires decoding and, for that reason, demands a creative intervention by those that want to know, understand, and do things with law. Altogether this amounts to recognizing the different modes in which law creates, and is part of, worlds. Second, I propose that due to different features of their aesthetic form, comics are a particularly effective medium to place students before the myriad ways in which law and lawyers make and reproduce worlds. Third, I illustrate the argument by exploring how the Saga comic series, through its formal multimodality and narrative and cultural complexity, can make good on that challenge.
\end{abstract}

Keywords Law · Cultural semiotics · Legal education · Worldmaking · Comics · Saga

\section{Introduction}

To say that legal education is in need of disruption is a truism these days. Clearly, covid-19 accelerated the technological fix many were claiming should be applied to education in general advocating for more creative ways of engaging students, delivering contents, and fostering collaborative learning and work in the virtual world and digital classrooms [20, 41, 45]. Often, this stance is advanced by authors concerned with the growing gap between highly technological law firms and conservative law schools producing old-school curricula and failing to educate the lawyers the market (arguably) needs and is asking for [14, 21].

Guilherme Vasconcelos Vilaça

Guilherme.vasconcelos@itam.mx

1 Law School, Instituto Tecnológico Autónomo de México (ITAM), Río Hondo 1, Ávaro Obregón, 01080 Mexico City, Mexico 
For others, this emphasis risks confirming McLuhan's dictum "the medium is the message", forgetting that what law, and thus legal education, requires is a more humane and humanistic re-orientation that breaks the servile relationship legal education displays vis-à-vis the market for legal services, thereby enabling the formation of critically oriented lawyers, not vocationally-trained legal professionals. A plea for heightened justice, moral imagination, and recognition of the Other [12, 25, 39].

A third group suggests instead that the legal industry's hand(s) on legal education prevents the latter to cater for unmet needs in the market for legal services given the fact such needs are perceived to be neither profitable nor exciting. Here, the driving force is less the noble goal of an uninterested higher education and more the very real empirical inequality gap in the access to legal services despite constitutional guarantees to the contrary [26, 42].

Each discussion portrayed above has, most likely, its core of truth(s) from each adopted vantage point but, in this article, I argue that transversal to all of them is an urgent need for legal education to focus on law's "ways of worldmaking" (an obvious nod to Goodman [19]) so as to equip students with the vision and ability to create worlds with the law given its worldmaking powers and nature. Indeed, students need to be made aware that regardless of the kind of legal work they (will) carry out - theoretical, practical, or methodological—and the different technologies they will use, they must embrace the idea that law is both a creative and constitutive activity. To assert such a proposition is to further claim that knowing law is a much wider competence than typically assumed; a competence that necessarily comprises constantly discovering and imagining law. In a broader context, Goodman $[19,22]$ had put it like this:

Furthermore, if worlds are as much made as found, so also knowing is as much remaking as reporting. All the processes of worldmaking I have discussed enter into knowing. Perceiving motion, we have seen, often consists in producing it. Discovering laws involves drafting them. Recognizing patterns is very much a matter of inventing and imposing them. Comprehension and creation go on together.

The premise of this article is thus that "doing things with law" should be explained and shown to match the way in which law creates our social world establishing a narrative that is distinctive from other narratives due to the symbols - and their legitimacy_-it deploys and relies upon. Because, law does establish narratives and worlds. While this may be both taken for granted and forgotten, the official legal world is but one possible semiosphere intersecting many other semiospheres; one based on special kinds of texts and documents, priests, canons of interpretation and thinking, roles, subjects, buildings, images, robes, values, and so on [20]. This, of course, has been the focus of the different law and humanities movements [48] from the early law and literature [54] to law and psychoanalysis [1], law and aesthetics [35], and law and dress [56]. However, the contention of this article is that these are piece-meal approaches that fail to 
convey the multidimensional ways in which law creates a world within the social world with its time, space, volume, life-forms, and narrative.

This article further claims that comics are the aesthetic medium that best puts us in this multimodal experience position and proceeds to make good on this claim by looking at the Saga comic series. In doing so, the article highlights a new mediumcomics - to be used in legal education and establishes that all narratives that happen in time must be lived perpetually, i.e., they cannot be simply legislated. It is important to stress that the article avoids critical legal studies' and humanities' lack of reflexivity in refusing to see their narratives as but other narratives that need to be decrypted. Indeed, the present article does not prescribe that reading and experiencing comics leads by default to emancipatory and critical meanings and contents (speaking of moral integrity in this context [31]; offering a classical CLS statement [29]). Instead, it proposes that looking into a certain kind of comics may help us develop a gesture towards the materials of law and their life; a gesture that does not foreclose an ongoing and ever reviewable engagement with the world.

The article proceeds as follows. In Sect. 2, I briefly characterize law as a cultural semiotic and aesthetic phenomenon to justify the need for legal education to introduce students to law's "ways of worldmaking". I illustrate the case for this shift by means of two concrete examples based on observations of law's presence in the social world. In Sect. 3, I make a case for the rather unique potential of comics in delivering the multi-dimensional and sensorial experience of creating worlds that is implicit in law. Section 4 exemplifies the point of the previous section by going through some of the themes and forms, and how the latter showcase comics' multimodality, deployed in the Saga comic series created by Brian K. Vaughan and Fiona Staples. Section 5 concludes.

\section{Law, Semiotics, and Aesthetics}

\subsection{General Remarks}

Law is a semiotic phenomenon [6], reliant on a profusion of texts and images that, knowingly and unknowingly, structure the way in which we perceive, feel, and arrange mentally the world [11]. Roberta Kevelson [30, 4] once identified two of semiotics' key assumptions in approaching social life:

1. All communication is a process of exchange of meaningful signs, and signs and sign systems such as natural language mediate between communicating persons and those objects in the phenomenal, physical world of experience to which they refer.

2. All human societies have developed complex systems of both verbal and nonverbal sign systems which are not static but which evolve continuously to correspond with and to represent changing social norms and the evolving, growing social consciousness of any given community. 
From such standpoint, to accept that law is composed of signs and that law itself is a cultural sign requires accepting the open-ended meaning of law, that is, that law and its signs always stand for something, the meaning of which is both in flux and enmeshed in further semiotic, social, and cultural relations. Yet, the provisional meaning one may find when discerning a sign can quickly be seen to constitute yet but another sign generating a never-ending game of symbolic reproduction and analysis. Furthermore, as Lotman articulated, signs and systems of signs do not exist in a vacuum but instead intersect and meet other semiospheres, other semiotic and nonsemiotic worlds, encounters that, while often taken for granted or left unexamined, require translation and mediation. In Lotman's words [33, 213-214]:

In the reality of the semiosphere, the hierarchy of languages and texts, as a rule, is disturbed: and these elements collide as though they coexisted on the same level. Texts appear to be immersed in languages which do not correspond to them, and codes for deciphering them may be completely absent. Imagine a room in a museum, where exhibits from different eras are laid out in different windows, with texts in known and unknown languages, and instructions for deciphering them, together with explanatory texts for the exhibitions created by guides who map the necessary routes and rules of behaviour for visitors. If we place into that room still more visitors, with their own semiotic worlds, then we will begin to obtain something resembling a picture of the semiosphere.

A major implication follows from this setup for those studying the law. When we talk about law's meaning we cannot limit ourselves to create the meaning of law out of its statutes, cases, principles, and doctrines. Instead, to understand the full richness of law's social meaning we need to examine the ways in which law contributes to the creation and reproduction of other cultural semiotic spheres as well as how law's meaning is also maintained and constructed by the latter spheres. In other words, we need to operate a genuine cultural, not merely linguistic, semiotics analysis, if we are to grasp the whole range of ways in which the legal sphere helps co-constituting the worlds we live in. In this broader cultural sense that owes much to the works of Barthes [2, 3], semiotics is, as Sedda [44, 677] puts it, "part of a broader historical and scientific movement whose task is to make explicit and explain the mechanisms and devices that structure our cultural life, our common ways of living, and our ways of living in common."

And yet, this is still not enough. For if law is imagined as one art of making and reproducing collective forms of life, if it is tied to the use of our creative powers and the modes of our existence, then it should also be the case that law has to be lived and grasped aesthetically, not simply rationally, through the forms in which it prompts subjects emotionally and sensorily. As Manderson [36, 21-22 footnotes omitted], an author who elaborates these questions at length, wrote:

Aesthetics understood as a way of knowing is therefore the conjunction of two aspects: the sensory force, with which we engage something, and the symbolic meanings, which become attached to it. The heart of the process of aesthetic experience is this union of senses and symbols-of the utterly 
present and the necessarily absent (for a symbol, like the imagination, can work only on what is absent). The object is a well of symbols which we apprehend in presentational form ... This symbolism will include elements which are deeply embedded in our personal experiences and memories and others which are cultural and more or less shared.

All in all, if students are to be sensitized to the varied ways in which law and lawyers make worlds they need to engage head-on law's relations to symbols and aesthetics. The challenge ahead is to devise a medium (or media) that can trigger such a composite experience and knowledge of the law. To my mind, comics can fulfil such a task but before further elaboration let us examine concrete examples of law's "ways of worldmaking".

\subsection{Two Examples}

In Fig. 1, a photo I took last January, we can appreciate, I submit, both the façade (and ornamented pediment) of Casa Tristán del Pozo in Arequipa (Peru) and the world created by law. The building located in the historical centre of Arequipa, in calle San Francisco, is an historical monument now turned into an arts house, having served before as the home of noble Arequipean families since its construction dating back to the eighteenth century. The path to reach this building is quite unique per se as the wanderer is forced to walk through narrow streets experiencing firsthand the sillar, a volcanic rock, white walls that gave Arequipa the "white city" epithet and transport visitors to a soothing timeless landscape. But this historical time and world of a bygone era is not the only one to be experienced as the peering eye

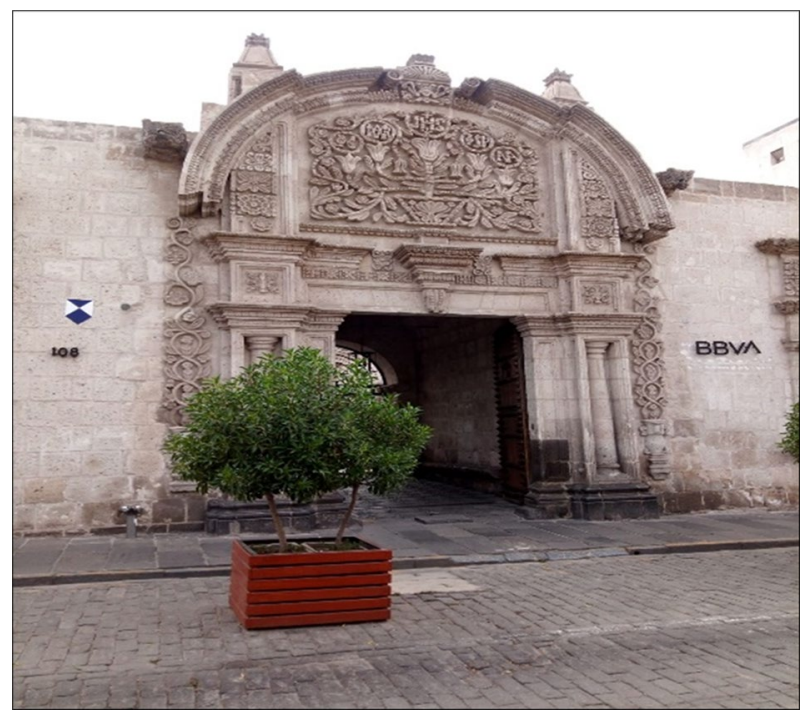

Fig. 1 Casa Tristán del Pozo, Arequipa. Author's photo 
can easily confirm when faced before the main gate of Casa Tristán del Pozo, due to the existence of salient contemporary symbols: a shield and a trademark logo.

On the left side of the gate, the cultural property emblem/shield guarantees that this building cannot be a regular military target in armed conflicts. Thus, the shield is a signifier that stands for specific meanings that are contained in international norms and conventions that protect particular types of property, e.g., due to their cultural heritage value, and regulate the conduct of hostilities. By the same token, the recognition of this building as a monument and of cultural interest, marks the site as a touristic destination [ 10, Chapter "The Semiotics of Tourism"].

The sign on the right side of the picture, BBVA's logo, is also a signifier with clear legal value standing for a legally recognized trademark which both attests to a bundle of property rights over the things the brand represents and identifies specific items as covered by the powers of the law of trademarks. Once again, one cannot interpret the layer of the world created by this legal sign without relating it to other signs such as property, the banking institution, and the importance of money circulation in current societies. It was a further stroke of luck and irony that the name of a bank - a fundamental institution in the capitalist social world-appears next to the shield of cultural property triggering the impression that banks seem to be a natural part of the world and ought to be protected from identifiable threats. Indeed, I was left musing what would the world look like if banks chose as site locations exclusively cultural heritage protected buildings.

Be that as it may, notice that none of the signs identified above and their meanings or signifieds are natural occurrences in the world. In fact, they superimpose a symbolic order upon materials of the world creating distinctions between what is permitted and prohibited, driving an edge between haves and have nots, enabling roles and social relations that embody and reproduce values that emphasize property and thus legitimate specific culturally determined patterns of behaviour associated to consumption, use, exchange, and exploitation from street vendors and musical shows to fine dining, multinational businesses, and global poverty. But not only, as the international protection of cultural property implies a specific discourse about common heritage of mankind which both shapes the value of the past, our attitudes towards its preservation since it presupposes property (as well as its kinds and philosophies) and, as with property, it creates forms of subjectivity and being-in-the world, e.g. the tourist and the tourism-based state and economy that in turn trigger new ones such as Instagram influencers and guides in touristic platforms like TripAdvisor and generate new practices of listing, or delisting as recently occurred with Liverpool, world heritage sites.

My point here is not to judge the desirability of this setup, but to note quite straightforwardly the way in which the law creates worlds, meanings, and forms of life in a space-time continuum impregnating our whole social experience and, in turn, transforming us to live and love accordingly. In other words, law is much more than a set of inanimate objects (such as rules or decisions...) or a set of static roles (officials, subjects...) and values (human dignity, justice...) even if it is also all of this. Law is neither merely a system nor a language but rather a cultural form of life that given its extraordinary social legitimacy—something authors as different as Luhmann [34] and Fitzpatrick [13] identify as having arisen first in the Western 
world - tends to have a prominent place in the constitution and regulation of other forms of life and subjectivities.

I hope this first example describes adequately how law, symbols, and aesthetics make our social world by adding layers of meaning that are represented while absent and thus that knowing law requires being capable of engaging in cultural semiotics. But the analysis is not complete since I have left unexamined the effects that may arise from law's reliance on signs that hide both intense struggles regarding their signifieds and, all too often, the forgetfulness that such meanings are not natural and thus require discussion. Furthermore, messages may also produce (and benefit from) a relationship of visibility / invisibility between signs, making some of them appear whereas hiding others crucially impacting the way we make sense of the message. As we shall see, this reveals much about the workings of the law. It is to this task that I now turn through a second example (Fig. 2).

It was in March 2021 when I first came across the latest advertisement by HSBC in Mexico. Automatically, and unconsciously, I juxtaposed it against Serge Latouche's famous book on "de-growth". I made a poster out of this juxtaposition and went on to ask my students and friends alike what they saw, felt, and read in it. It was no surprise, honestly, that nobody was familiar with Latouche's theses though this confirmed right away the cultural power of signs. The message of HSBC was interpreted as naturalizing money given both the linguistic expression "dinero líquido" (liquid funds) and the fluid consistency and texture of the monetary sign in the ad. Furthermore, I added during a class, that in Chinese the word "fă" represented by the character 法 and commonly used to mean "law" is composed of two characters-"water" and "go"-given that it is a law of nature that the water flows downwards. However, I believed there was something wider and deeper in the message when I first saw it and that had triggered me to use it; something that attests to the hidden power of signs and that prompted the juxtaposition with Latouche's work on de-growth.

First, I find that the message clearly divides human being into those that "know" and those that "don't know", sharply and successfully relying upon our current social emphasis on the importance of knowledge. This can be seen in concepts with wide currency such as "the knowledge economy" or the longstanding and still powerful
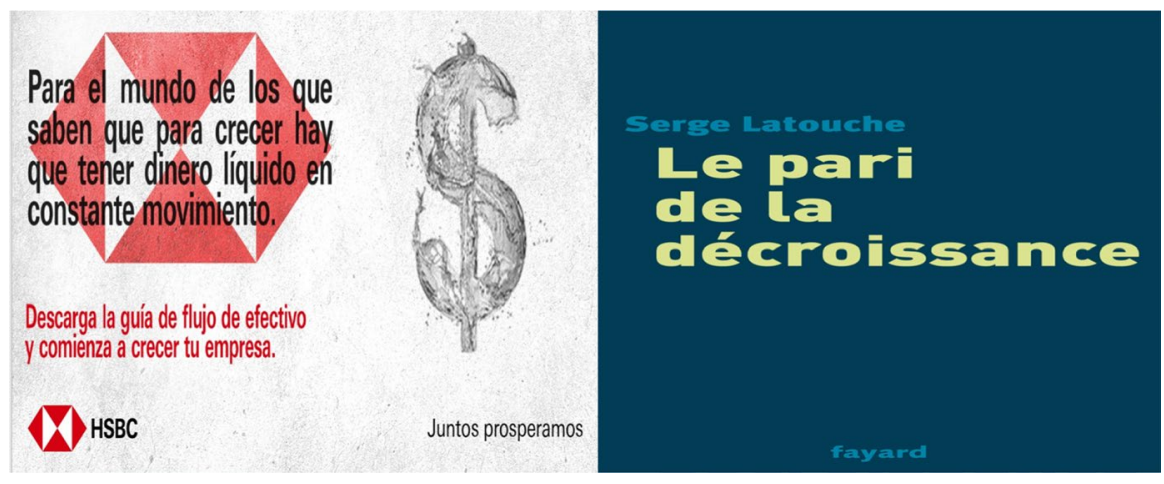

Fig. 2 Author's montage 
Greek ethical view of knowledge as virtue and ignorance as vice, a conception that was highjacked being modelled after scientific discourse and not self-improvement and cultivation as held earlier. Altogether, the effect is that no rational or socialized, being, would wish to be ignorant.

Second, and this is the central point, the message does not simply assume that money is natural but that it is natural and desirable "to grow" which, given the mantra at the bottom right corner "juntos prosperamos" (we prosper together), and the earlier emphasis on knowing, drives home the idea that prosperity and growth come hand in hand, i.e., growth is the natural and desirable way to prosper, and this is knowledge not opinion. This is, I hold, the hidden myth of the message, drowned under the more obvious connotations of money's circulation and fluidity as being natural. Indeed, that growth is equated with prosperity, and a natural condition of the latter, is an undiscussed belief and value of our societies that generates invisible results. For example, the fact that nobody consulted knew Latouche's work on the opposing stance: given the finite nature of earth and its resources we need de-growth.

While law seems inconspicuous and even absent from the picture, a second of reflection should be enough to remind us that this advertisement is an institutional one, part of the legal and legitimate commercial strategy of an established and influential global bank premised upon a specific legal arrangement that protects and encourages the growth-prosperity binomial-among other things by enabling and favouring the acquisition and concession of credit. That prosperity and growth, however, could be understood as greater redistribution and equity in the access to wealth or higher levels of happiness is something that neither mainstream cultural politics nor legal arrangements explicitly tackle; and ultimately is what naturalizes this ad's signified. In the legal world, this can be seen by scrutinizing the myriad ways in which the "right to life" is rarely interpreted and, even less, legally protected, across the world, as comprising "the right to a materially decent life" in addition to the recognized liberal right "not to be killed". By the same token, that knowledge is virtue and ignorance vice, is also but one possible ethical and practical meaning. For example, in the Zhuangzi [55, 184], another ethical source that in Ancient Chinese philosophy disputed the moralism of Confucianism, one can read "Not to understand is profound; to understand is shallow. Not to understand is to be on the inside; to understand is to be on the outside."

Ultimately, one could say the signs examined above and their intertwinement with the law have become mythic in Barthes' sense [3, 4]. Indeed, few realize they forgot they had forgotten, Bergson's idea of genuine forgetfulness, that it is the law and the specific meanings we grant(ed) it that enable(d) specific forms of life that are now rendered natural by means of apparently innocent advertisements, which, however, only hide the mythic origins and assemblages of the materials used. This is particularly the case whenever we talk about cultural products such as poster-like advertisements which materiality is experienced as two-dimensional, a visual vitrine, rather than an immersive three-dimensional locus such as Casa Tristán del Pozo.

While there is always the potential for critical analysis, I submit that first students must be able to visualize the symbolic order that connects signs to other signs, as in a spider's web, turning law and culture into disputable narratives that could always 
turn out to be read differently even if widespread convergence towards specific readings seems to be in place. In this sense, my juxtaposition of Latouche's book cover provides an example of such a cultural semiotics strategy that students should develop. Opposing signs to other signs, placing signs in different semiospheres, or creating new relations between signs in order to question received meanings and dissolve their mythic effect. Finally, the deployment of Latouche's cover also illustrates the importance of the form of signs - a crucial point as we shall see through comics - since it would be different, from an efficacy, impact, and aesthetic standpoints to produce the same discourse relying on written language solely. After all, the image is a form that enables engaging the hidden meanings in HSBC's advertisement via a "visual game" (Emilio Tejeda's expression when commenting on this point).

But students must also be sensitized to the fact that any reading claiming to see law and culture in the "right way" assumes, mistakenly, that law or culture as the "real thing" exist out there, as if law and culture could be experienced outside of structures of signification that frame the selection and arrangement of their elements [10]. Thus, it is the position towards law's and lawyers' ways of worldmaking that students need to experience and acquire, not particular contents or semiotic readings. As the coming sections explain, I believe that such a position can be best grasped by examining (and placing students in) the position of the reader of (certain) comics.

It could be postulated that it is at the point in which law seems entirely absent from the picture that law reaches its most powerful mythical force having shaped our subjectivities to disappear literally in the background, apparently letting us experience cultural life as if it was an autonomous, unconstrained, and unshaped phenomenon. It is this receding of law that helps producing the sensation that certain meanings are shared and natural and, simultaneously, stops triggering in us perplexing emotional or rational responses. For we no longer can tell, and therefore inspect, what the source of our beliefs and dreams is (but are these "ours" or "social"?). Such a relationship between law, culture, and signs (visible and hidden) is superbly articulated by Aristodemou [1, 5-6] as follows:

without support from cultural products, the legal order would not be able to constitute itself let alone survive ... culture functions to present society as a cohesive 'whole', obfuscating the abiding problem that society as a 'whole' does not exist ... culture generally, and popular culture in particular sere to cover society's gaps and contradictions ... the fact that our cultural products are gently and invisibly inscribed on our subjectivities, makes culture, as Slavoj Žižek has been arguing for over two decades, the central ideological battle today.

If this intertwinement between law, culture, and signs holds, students need to be able to create worlds when they consider law and the way in which values, roles, actors, actions, rules, principles, and all other elements of legal and cultural life hold together by means of codes and forms- linguistic, imagistic, sensorial-which keys we seem to have forgotten a long time ago. This is true for the macro analysis or legislative analysis of law understood as the creation of a specific kind of normative 
order and project. And it is also true for the case of more micro analyses as when one adopts the point of view of the practitioner in which there is much to gain from reading and approaching "doing things with law" as a narrative. Nevertheless, never as in the mythical "chain novel" metaphor employed by Dworkin which fictions convergence, uniformity, and linearity among the different materials to be marshalled in accordance with his normative view of law as integrity,.

Instead, seeing law as a worldmaking enterprise and activity sensitizes us to the fact that legal problems must be discovered and conceptualized as problems that intersect a variety of worlds. Furthermore, while there is agreement as to the most important methods of legal argument, such as the canons of legal interpretation, it is blatant that such methods are not self-applicable and in any case do not answer the question as to how one is to approach a specific problem. In other words, the difference between approach and methods [46] is the difference between the strategy to grasp and attempt to address a problem and the set of techniques that are to be applied as part of the strategy devised and according to the latter's specific goals. The point being that problem, approach, and solution remain unknown prior to the effort $[8,2]$. To that effect, for James Boyd White [57, 262]:

The mind must be a source of its own energy, of invention, of what the rhetoricians called ingenium: the power to make something new. This has at least two sides: the power to ask new questions of the world, of the client and the witnesses and the files-to ask questions that will generate new material; and the capacity to organize it all in new ways, as a new story, with its own starting point, direction, movement, and ending-to recreate or represent the world in language.

But White fails to answer in detail his own question on how exactly the powers of imagination are "to be stimulated" and honed. In my vocabulary, how can law students be educated to imagine and create worlds?

\section{Worldmaking and Comics}

It should be clear by now that seeing law as an art of worldmaking requires from law students and lawyers the need to think hard about what kind of community, society, and forms of life they are (and will be) producing and reproducing through their actions. The three-dimension task sketched above is not, of course, unrestrained especially in positivist legal cultures that have turned law into a documental and highly institutionalized practice with its established sources and officials. But at the same time, as the semiotic examples provided in the previous section have shown, law cannot be cut from its cultural semiotic environment in the same way a plant cannot be severed from the soil and water that keep it alive. While the connection between semiospheres is not biological, it generates an equivalent effect since the meanings and ways of worldmaking of law cannot be dissociated from those of other semiospheres due to the networked operation of signs in cultural life.

How can then one stimulate students to undergo this sort of experience and training in richly norm-bound worlds? Especially, considering that as elaborated above, 
our experience with law is not simply textual but visual and aesthetic in a richer and broader sense. To grasp such general and specific fusion between law and culture mediated by signs is something that students ought to achieve and master during their legal education. But this is also a task that is greatly obstructed by the technicalities of semiotics and other cultural theories' apparatuses.

Upon reflection, one could say that worldmaking is the regular experience one undergoes by playing "open world" or so-called "sandbox" videogames in which players can, with varying degrees of freedom and flexibility, interact with vast atmospheres and landscapes and see how their actions and choices impact the evolution of said worlds. But "sandbox" and "open-world" videogames require dozens, easily hundreds, of hours of gameplay making them difficult to administer in a classroom-based experience (even if flipped).

A more practical medium, but still able to provide the immersive and worldmaking properties described above, I submit, are comics. Classically defined as "sequential art" or a "juxtaposition of text and images" [37], comics have come to be studied from the standpoint of their distinctive aesthetic form or medium. That is, what do comics do and communicate in virtue of the fact they are comics and not movies, paintings, or novels? Key here, and particularly useful for the argument being sketched in this article, are the recent contributions emphasizing comics' multimodality and the multisensory experience they offer. For Giddens [16, 1] "[a]s a medium, comics is multimodal, in that it employs, exploits, or presents a variety of different modes of communicating-visual, textual, graphic, linguistic, spatial, narrational, and so forth-in a complex layering of multiple frames." And for Hague [24, 7, emphasis in the original]: "Readers do not interact with comics through their eyes alone; their whole bodies are involved in the performance of the work."

These are crucial developments because they go hand-in-hand with the features identified above as important in legal education and that, as claimed by Glancey $[17,57$, emphasis in the original, footnote omitted] require an important conceptual change in pedagogy:

Whilst traditional pedagogical approaches, such as lectures, focus upon content and are evaluative, experiential pedagogy focuses upon the process and is developmental. My assertion is that using graphic fiction to teach law is a process-based pedagogy designed to assist the development of students.

Research on the learning and teaching impact of comics in higher education is basically non-existent, to the extent I could verify (apart from rare first-person accounts of teaching with comics [17]), but that does not mean that we should be suspicious about its benefits. On the one hand, this path was opened by comics scholars that are gradually overturning the assumption according to which comics are aesthetic products of low artistic and cultural level that fuel the dreams of either children or misfits' grown-ups. The combined work of this scholarship (see [23, 37] for classical examples, and [15] for the latest work) has called attention to the gigantic variety and richness of genres, techniques, and themes in comics as well as to the intricate and complex artistic forms deployed together with the demands they place on readers. On the other hand, this was also helped by the spread of explicitly political comics: documental-journalistic by Joe Sacco, e.g., Palestine and Safe Area 
Goražde, and historical such as Maus by Art Spiegelman on the plight of World War II, or even the Showa series on the recent history of Japan by Shigeru Mizuki. To these examples one could add strong politically motivated works such as Truth: Red, White and Black by Robert Morales and Kyle Baker introducing a black Captain America to pay tribute to the horrifying Tuskegee Experiment by positing that the super soldier serum Steve Rogers received had been previously tested in black human beings so that it could then be safely administered to white test subjects [7].

If the themes and the depth comics acquired successfully conveyed the image that they were no longer the province of fantasyland tout court, comics' distinctive aesthetic features also assisted. One distinctive and rather unique device employed by comics that forces the reader to fill in the gaps is the gutter $^{1}$ or the line separating (physically or metaphorically) the boxes since it introduces discontinuity [22, 111 ff.] and marks, especially when associated to the specific sequence and transition between boxes and panels, a dialogic relationship between reader and comic that does not take place so intensely in other aesthetic media such as movies. For, as Groensteen $[23,54]$ writes, "[w]hen [s]he "meets a frame, the reader is taken to presuppose that within the perimeter that has been drawn, there is content to be deciphered. The frame is always an invitation to stop and to scrutinize."

This assists in explaining why montage, an operation with major aesthetic and narrative effects in movies, activates less the observer's intelligence and senses in trying to create meaning out of those breaks in the flow of the work and the disposition of signs of different textual and imagistic abstraction. In Fellini's words (quoted in $[23,11])$ " [c]omics, more than film, benefits from the collaboration of the readers: one tells them a story that they tell to themselves; with their particular rhythm and imagination, in moving forward and backward."

The purchase of these two specific features of the comic form for legal education lies in the fact that the position we built as necessary to know and understand law's ways of worldmaking is symmetric to the position of the "experiencer" of comics. The latter can effectively point to the former the creative and aesthetic nature of the operations we carry out to make a reality out of different materials and signs.

The compression of text and language that the comic form requires (but also plays with) further adds to is potential in triggering a complex intellectual and emotional response from the reader (or experiencer) that is called to process and enact vast worlds and narratives as if assembling a puzzle in which random letters, images, and other pieces are missing. This seems, to my mind, particularly important in times in which the truth of images and texts has come under heavy fire and is now met with widespread disbelief. If one buys into Baudrillard's "desert of the real" [4, Chapter 1] and effectively sees reality as simulacra of simulacra, as an endless succession of acts of production, distribution, and circulation of signs, rather than acts of truth that put an end to the quarrel; if one accepts that life and reality itself have become virtualized, then comics' explicit worldmaking does not appear so far-fetched.

\footnotetext{
1 See McCloud [37, Chapter 3]. Another distinctive mental process triggered by comics is closure, or the creation of reality by the reader out of separate lines, shapes and events scattered in and across boxes, panels, and frames [37, Chapter 2].
} 
Finally, as my own experience over the years teaching the "Law, Culture, and Aesthetics" and "Global Ethics" courses attests to, students now report that they may be more triggered by movies, performances, songs, or artworks (based or not on real events) than by supposedly photojournalistic, documentarist, or even documental sources of events. The reason being that, in a context in which it is known (and experienced) that images (and other documents) are continuously photoshopped, edited, and manipulated, their aura of truth no longer stems from the kind of medium that produced them. As such, the feeling of truthfulness is associated by students more to the empirical impact they feel whenever exposed to media as well as to the degree of manipulation they seem to detect in such media outputs. As a result, a graphic novel or an art installation can indeed feel more real and trigger more moral reflection than documents we once held as true and authentic.

In other words, the distinctiveness we assigned to creative arts as the realm of imagination and used to distinguish them from hard sciences or arts that aimed at truth, crucially depended on our belief that some media, such as photography, did indeed capture the world as it is, without filters or manipulation. Of course, this required both the belief that there was a world out there to be captured-a real world in opposition to the fantasy world of literature for instance-and the belief in the neutrality and objectivity of the medium employed [58]. Beliefs that are now in crisis. A good example, offered by Gianni Vattimo [49], was the discourse built around the authenticity of the photos, documenting the existence of weapons of mass destruction, that Collin Powell presented to legitimate the American attack on Saddam Hussein, presupposing that there are such things as true, unmanipulated, images.

\section{Saga, Worldmaking, and Legal Education}

Having laid down the pillars of the argument, what could be an appropriate comic series to lead students to experience worldmaking as coessential to law and doing things with law? In the remaining of this section, I argue that Saga is up to the task, offering a template for comics to be used in legal education oriented towards the goals identified throughout the article. This is due to (i) its exploration and reimagination of pressing and coming cultural and political wars - through thematic choices, character construction and development, and narrative continuity [38]forcing the reader to live eerily in between worlds while experiencing the series; and most importantly, (ii) the specific use made of the form of comics ensuring that the reader experiences in an immersive, compressed, and multimodal fashion how narratives create and connect different worlds and times and thus are always in excess of what we see in the present moment.

Saga is an epic comics series written by Brian K. Vaughan and illustrated by Fiona Staples [47, 50, 51]. In a nutshell, it tells the story of Alana and Marko, two deserters from the war pitting their home countries and species against each other, and the different peripeteia that impact their family in their attempt to save Alana, their daughter. Like Frank Hebert's Dune and George Lucas' Star Wars, Saga 
fictions an intergalactic order in convulsion building a world, or better a universe, populated by different species, human and non-human, pseudo-human, and robotic; all species sharing human-like qualities while differing in many other respects such as languages employed and the use of magic.

But Saga goes well beyond those franchises that focus more on acquisition and maintenance of political power and sovereignty (one could mention here Hickman's, Dragotta's and Martin's East of West). Even if, it is interesting to find the occasional mention to penal colonies, such as planet Cleave, that by means of an unreal signifier may trigger in the reader associations to signifieds we are familiar with in human history such as Australia, the ambitious British penal colony [27]. Indeed, given the abundance of signs in the Saga worlds as well as the on and off connections between those realms and what human history and world look like, Saga sharpens the imaginations of readers as one is constantly challenged to make sense of symbols and events that seem to point to some part of past, present, and future choices of both so-called real and unreal worlds.

In addition, Saga plunges the reader with all its might on many of our contemporary cultural wars offering a progressive, political, LGBTQ avant-garde world. In this it resembles Degen's Soft X-Ray / Mindhunters, drawing a wildly fantastic subversive and surreal world of weird libertine life forms exhibiting strange powers while embarked in epic quests. Alana, is a feminist mother, rejecting, pre-emptively if needed, any appearance of patriarchal attitudes and outcomes, pursuing dreams and wishing to die rather than to live conservatively simply because she has a daughter. Interspecies explicit sexual intercourse, between winged and horned beings or even beings with screens instead of heads, breaks several important taboos regarding sexuality and the future of the (human) body and gender in the same way that the discussion of "clipping wings" as part of a policy to eliminate species' differences recalls hot topics of today (such as female genital mutilation) and of yesterday (such as foot binding).

While truth in general does not seem to have, at first glance, much currency in the Saga universe, it is brilliantly incorporated and explored in the form of two characters that could be used as experiments in the redefinition of subjectivity and technologies of the self and their interplay with the demand (need?) for social trust. One is the lying cat, a rare species that can detect instantly and flawlessly any lie being said in his presence. The other are the imperial robot family members, such as Prince Robot IV, who display screens instead of heads. Excitingly, their screens exhibit, unfiltered, their thoughts and dreams making them an open window to everyone else. If social truth is now perceived to be an illusion in the eyes of the beholder, what about private truth? Shall we conceptualize the matter altogether in this new way? With which implications for our subjectivities and our idea of what counts as a legal subject? [52].

The ethical demand or impulse to which all of us are prone to respond, even if unwittingly, is pursued by Marko's promise to renounce to violence and killing; a commitment that different events along the narrative test again and again especially when the well-being of his family is at stake. The structure of Marko's ethical dilemmas is akin to those we all face requiring striking a balance between ideals and their pragmatic application in specific contexts as well as finding a fine-tuning between 
cosmopolitan and communitarian concerns. Given the length of the series and the fact that time goes by in Saga's worlds, Marko's choices are not one-off decisions but rather repeated iterations in changing contexts enabling us to witness-and therefore prompting evaluation-real quick changes in his character and ways to go about his values negotiating family, friendship, loyalty, and common good concerns; not without, however, much agonizing.

The examples described above are just a tiny sample of the amount of thematic, content, character, and narrative analyses Saga enables. Examples which can be used to make students experience the unfinished and open-ended nature of their task as lawyers and the effects of their decisions on contentious cultural, political, ethical, and legal issues. They can also make students realize how much of their options and positions regarding such debates are dependent on the broader cultural semiotics spoken of in Sect. 2. Regardless of the benefits of this approach, the critical reader could point out rightly that these features of Saga are hardly exclusive of comic art. And indeed, comics' unique potential in offering access to the experience of worldmaking that, I suggest, is necessary for law students, comes not from the themes or literary contents of Saga but rather from the specific way its authors deploy the comic form. As I detail below, it is the latter use that enables students to experience "ways of worldmaking" in a multimodal and multisensory way further allowing them to perceive, experience, and confront the thematic contents of Saga not as merely intellectual debates but as situated world events, i.e., alternative possibilities of collective forms of life in given social narratives. How is this so?

Hazel, Marko's and Alana's daughter, speaks through text that criss-crosses images and balloons throughout the series adding both a meta-level to the narrative that is being told and is taking place, and another timeline since her wordsappearing scrupulously outside of balloons or other text boxes-are proffered with hindsight and imposed upon the past. This mixing of temporal planes and textual elements (dialogues and Hazel's remarks) is particularly unique to comics as an aesthetic medium and can be analogized to law and legal discourse with fruitful results as we shall see below.

Saga begins with Hazel's birth with a single-page panel in which Alana her mother whose face is marked by her effort, while giving birth, says "Am I shitting? It feels like I am shitting!" $[51,5]$. The colours used are warm and vivid fitting the rawness and emotion of the moment. Simultaneously, however, a sentence, printed in small white font, appearing above Alana's head, and uttered from an unclear speaker reads: "This is how an idea becomes real." [51, 5]. While the action continues over the following pages and Alana effectively gives birth amidst aggressive and cynical rants against Marko, Hazel's speech continues to be superimposed on each panel creating a beautiful and deep juxtaposition between images, text, and temporal planes which link giving birth, life, and the properties of ideas. Thus, Hazel's full text reads "This is how an idea becomes fragile." / "But ideas are fragile things." / Most don't live long outside of the ether from which they were pulled, kicking and screaming." / That's why people create with someone else." / Two minds can sometimes improve the odds of an idea's survival..." / "but there are no guarantees." [51, 6-7]. This last bit of text is inserted in a dramatic strip, in which Marko is crying while looking into Alana's open legs, suggesting that perhaps indeed the birth, like 
an idea, had failed to produce sustainable life. The next panel has Alana asking, with a worried, less confident and proud face than before: "You're crying. You never cry. What's wrong? Marko, what is it...?" [51,7]. The page ends in deep suspense at this point-another typical aesthetic choice in comic art-and we are forced to turn the page, making our body an accomplice in the reading experience, to satiate our curiosity. And indeed, in a powerful page-long panel, to the relief of this reader, a crying Marko, tears dropping down his face proclaims: "It is a girl." [51, 8]. While holding a baby that stands out due to her reddish colour with the umbilical cord in plain view, Hazel writes "Anyway, this is the day I was born." [51, 8].

This beginning is a magisterial tribute to the political philosophy of a multicultural, multiracial, and multispecies world since Hazel is a crossbreed born with her father's horns and her mother's wings. But, of more direct importance to future lawyers, this beginning stages powerfully the way in which Saga deploys the idea that social communication can never be studied and understood as a discrete event separated from the actors that perform it, in isolation from the contexts in which it arises, the worlds it connects to and relies upon, and in oblivion to how other past and future communication may be mobilized to cast a new light or judgment on present events.

For instance, Hazel's comments noted above (that continue throughout the series until she is born), function as a sort of Greek chorus advancing general lessons and casting probing judgments of the ongoing human experience and action thereby forcing the reader to confront her ideals, beliefs, actions, and linear historical reading of the narratives she is simultaneously experiencing, enacting, reproducing, contributing to, and being placed in. In this way, there is no single (present) world, e.g., Hazel's birth and her parents' interaction, but a myriad of worlds that communicate with that sign/event according to criteria of their own worlds. Social order then shifts from being a flat and discrete surface to a multitextured and rugged landscape that is almost tactile in which time and space are lived, shaped, and overlap continuously in virtue of social interactions, (arguably) stimulating and driving complex intellectual and aesthetic responses in agents.

Yet, at this point, the attentive reader could draw attention (as a reviewer did) to the fact that despite all my talk of comics' multimodality and the latter's potential to transform legal education, the analysis provided above emphasizes the same old traditional linguistic and textual elements. How then can the visual aspects of Saga help illustrate comics' power to generate awareness of law's multimodality in worldmaking?

Formally, the juxtaposition of Hazel's birth, the interaction between Marko and Alana, and Hazel's reflections made from the future, is inserted in several pages without linear page breakdown and layout. Indeed, the number, size, and disposition of panels does not follow a clear pattern ranging from single-page panels to pages with two panels and others with more panels, even if always arranged differently. Altogether, in my opinion, these visual, "spatio-topical" elements in Groensteen's words [23, 21-23], deepen powerfully the textual and semantic analysis already performed. Indeed, the fact that there is no clear pattern regarding the page layout and page breakdown reinforces the idea that events (and life) always come in disarticulated fashion and can never be "seen from nowhere". In other words, narratives 
are inseparable from the ways in which we arrange them, and these operations are unending attempts to make sense of what is going on. Furthermore, I interpret the effect of these formal choices as potentiating and reinforcing the coexistence of multiple timelines as remarked earlier. This is because arranged in this way, and in "iconic solidarity" [23, 17] with the textual elements, the panels' layout create the perception that reality is unfolding panel by panel and thus is being enacted in a non-predictable and linear way by characters that exist in different times and spaces. Ultimately, the specific page layout and page breakdown choices frame superbly the analogy between ideas and birth and their fundamental uncertain, agentive, and risky nature.

This effect is further extended by the adoption of clear, regularly shaped, symmetrical white gutters, that isolate each panel, turning each into a separate piece of the puzzle one needs to assemble in order to make sense of the worlds being enacted. On the one hand then, the geometrical white gutters provide some sense of order and containment, offering readers a formal visual code that invites them to structure the reading experience. On the other hand, the same white gutters are a reminder that the slightest event and interaction can be the subject of comment, evaluation, or any sort of exchange by other agents located elsewhere time and space wise, such as Hazel.

Altogether, the visuality of Saga is particularly powerful in what concerns worldmaking and law because while it enables students to experience the multidimensionality of the cultural world they are studying, it also provides ample room for them to build patterns out of the myriad elements and forms of the worlds portrayed. This is important because as Goodman reminds us in the quote mentioned earlier, "recognizing patterns" is very much creating and inventing those patterns. To deepen even further the way in which Saga invites readers to build patterns out of visual elements consider the following examples.

First, the complex construction and reproduction of the world via the form of comics is evidenced by the fact that the font's colour of different clans' speech varies. Thus, while most characters' speech appears in regular black font, some of Hazel's musings appear in white. Ghosts, known as "Horrors" and living during the night, are portrayed in transparent red, highlighting their "dead" condition, which is also the colour of their dialogues $[51,76]$. Furthermore, Marko's family speaks blue $[51,177]$, a language also used to perform spells and magic that is impossible to recognize without special translating devices.

Clearly, the visual properties of Saga help to make sense of the multiple characters and the groups they belong to, coding them in a way that highlights and describes their existence in the world, transcending the textual. An operation all too frequent in legal worldmaking as we have seen when we spoke of the tourist and other subjectivities born out of tourism and culture. But visual properties in Saga, also introduce features that transcend the state of the situation and the space of possibilities of what is feasible in the world built in black. Consequently, ghosts can bond with living creatures bringing with them special powers and abilities as well as the experience of past lives-a supernatural existence that is branded through the use of the red colour as mentioned above. And those speaking blue remind us of the power to change the laws of physics and reality as we know it, a key ingredient to 
remain hopeful and critical at the same time. The colouring of speech (and characters) has therefore the power to evoke deftly and instantly the multiple worlds and their radically different backgrounds, features, and social hierarchies, throughout the panels of the series.

Second, in Saga, generally speaking, one can notice that bleeding and singlepanel pages are typically used to portray peak events [9, 71-73] and to introduce first appearances of major characters or characters that trigger important actions by major characters [51, 75, 114, 216]. Similarly, gutters are coloured black exclusively in particularly gruesome moments of the narrative when lives are taken. In Volume 1, this is when Marko and Alana, the Coalition forces, and Wreath contingent faceoff leading to considerable casualties [51, 16-17] and shortly after when The Stalk, a deadly freelancer bounty hunter, meets Marko and Alana for the first time. Along these lines, and as mentioned above, it is particularly interesting to note the fact that $[51,172]$ the blue language when portrayed in blue is never translated and thus is of impossible (immediate) apprehension by the reader.

To my mind, this both highlights that the textual and the semantic are not always the most important aspects in worlds and that they sometimes can be omitted to bolster the uniqueness of specific world-elements and thus that worlds exist within worlds for which we cannot always find translation and meaning. Either way, the fact that there is no translation and thus that the textual element is downgraded qua meaningful text quite interestingly and paradoxically makes the reader (almost) hear the characters speaking out loud those incomprehensible sounds. Such a choice effectively blends the linguistic, visual, and sound elements to produce an immersive experience in worldmaking, communicating in multimodal and multisensorial fashion the idea that the modes of existence of groups and characters in the world is multidimension and plural.

Third, and following the cue of sound's importance in worldmaking, an excellent detailed depiction of how visuality and sound interact in Saga can be found in [51, 17-18], a two-page representation of the carnage ensuing the mentioned battle between the people of Wreath, Coalition forces, and Marko and Alana. The exceptionally rare black gutters, suggesting right away the sombre and tense mood of what is to come, are pierced by the trajectory of ballistic projectiles and spells in an ultradetailed slow-motion that makes us follow the havoc they are causing taking the reader in a snake-shaped path top-down, from left to right, right to left and left to right again. Time and space freeze over these six-panels that zoom in on a specific event before expanding again revealing the devastation left behind and the consequences characters are left to face. Once again, the visuality of Saga, here in similar fashion to Matrix's famous lobby scene, guides and directs the construction of the narrative by both distinguishing the importance of events in the narrative arc and making them weigh differently too, emotionally speaking, in the reader.

But in Saga, this play with time and the absence of music and words except for a single onomatopoeic sound makes the scene even more real, as if the muteness heightened our capacity to add the sounds we are too familiar with (those of war and battles with screaming and expressions of pain, despair, rage, and devastation), placing the reader in charge of completing the narrative in a multisensory way. The overall effect is similar to those mute film scenes of destruction and havoc that rely on 
the dramatic effect of making readers and viewers experiencing the contrast between what is happening and the unnatural silence, a contrast triggered by our knowledge of what and how the scene should be sounding like.

Ultimately, the visual aspects of Saga clearly force students to perform closure, that is, to extract and construct meaning across panels and pages, their different modalities, and elements, while keeping in mind that the worldmaking that is being enacted does not need to occur simultaneously and synchronically. How are these conclusions relevant for legal education and law's ways of worldmaking? As social life, law's world is also one in which agents, spaces, timelines, and a plethora of signs intermesh. Indeed, it is widely held that law is an enterprise largely based on tradition in which decisions connect the past, present, and future [32]. Furthermore, while some decisions may seem to be down to earth and consist in the application of well-established principles and rules, such decisions are always open to, and part of, a meta-reading inferring principles and shared wisdom from it. Or simply placing the concrete narrative one is involved in within a much larger context both factual and normative. Therefore, the law is never just about the present tense and the present case (also because different legal organizations can frame such present differently) but always about the times and actions of multiple ongoing collective forms of life.

This is not to say that the result of this awareness of the different temporalities and levels of discourse in the law invites us to disregard the concrete case or functionalize it to the demands of systems or the future. Nor am I am saying that there is some sort of ontological relationship between the legal and comic worlds. What there is instead, is a continuity in their intertextuality or multimodality, the narrative and visual worldmaking ways in which they work, and that experiencing them in comic art-due to the latter's forms - can make it easier to experience, recognize, and create them in law. Indeed, the point is that awareness of the fact that law is an ongoing communicative and living practice is fundamental to know how and when to make use of these different dimensions of analysis or, simply, that law is always open to such kind of reflection and experience. Comics' multimodality unfolds therefore, as Giddens $[16,5]$ has asserted, "a space where we may be free to engage, imagine, and create law in different forms - to "re-form" law."

Exactly, the kind of reflexivity and "education of the mind" James Boyd White spoke of and which I have endorsed earlier and that should come before any vocational training. It is important to stress that exposure to these multiple planes is congenial to comics but very hard to achieve in traditional doctrinal methods of analysis and other aesthetic media. This is because the comic form allows for the compression of different media that typically would be kept separate since the interested student or citizen would have to first find images or videos portraying a given situation, then she would have to go through different documents issued by various authorities as well as other sources such as monographs, podcasts, documentaries, or clips on more detailed topics. Strikingly, comics like Saga can produce this multi-media effect in a single panel. What is more, and due to the use of gutter, closure, page breakdown and layout, sound, and the play of image and text concerted with the turn of the pages, comics also add a clear emotional, and more broadly aesthetic, 
experience to the act of reading, transforming it radically in the process. As put by Romero and Dahlman [43, 10, reference omitted]:

The written text can function like images, and images like written text. This is precisely how the comic medium operates differently from any other media. In comics, images provide contexts and subtexts for words, thereby problematizing textual messages. Words, conversely, shape how we perceive and interpret images. These combinations allow for communicative innovations such as using fragmented or abstract imagery, textual shifts in temporality, or pictures conveying emotions and mental processes that could not be easily understood through plain textual statements.

\section{Conclusion}

Throughout the article, I claimed that legal education and legal thought in general must acknowledge that law creates worlds, and that this recognition requires students to experience being the position in which they perceive the worldmaking ways of law. Complex comic series such as Saga can provide such an experience making us all more aware of our own responsibility in writing and acting the narratives of the worlds we live in as well as of the role of signs in this cultural and ethical task. Comic art though is not a panacea for legal education and certainly this article has not endorsed such view, but it can undoubtedly contribute to equip students with "multimodal literacy" [28, 22]. I would like to end by addressing a question that may remain lingering: is this worldmaking paradigm shift in the way we approach, grasp, and experience law's presence in the world also fit for legal practice and legal reasoning in a narrow sense? Since I have claimed it without providing much support for such a claim, let me end by briefly tackling this question. Two dimensions ought to be distinguished.

Opening up to law's ways of worldmaking in a holistic sense, shapes in abstract our whole understanding and experience of law, both theoretically and practically. As in philosophies of self-cultivation and ethical growth, the promise is that after enlightenment one's practice becomes richer, more meaningful, and simultaneously more aware of and tuned to the complexity of life. In this sense, endorsing law's worldmaking would enable students to see law in a much more malleable way which could also impact their future doing things with law.

Regarding the impact of law's worldmaking in a more practical sense we need to distinguish between different kinds of legal practice [53]. From the legislative, abstract, and normative standpoints, it is easy to accept the performative nature of law and its reliance upon and interaction with other cultural semiotic spheres, given that law is merely one, even if particularly potent, technology among other to produce signs, meanings, and forms of life in the world. From the conventional legal practitioner's point of view, things are different since one does not always face hard cases nor can one engage in meticulous thinking about how law is making and should attempt to make worlds. It should not be forgotten that being competent in 
the practice of law is not a matter of truth but of knowing how to deploy the vocabulary of law as determined by existing conventions and intersubjective agreements [40]. Thus, it should not surprise us that in conventional lawyering in current positivist legal cultures the scope for explicit and direct worldmaking in ordinary concrete cases will most likely be rather limited.

Even then, as maintained throughout the article, the use of the legal language presupposes forging a narrative given that while we do have shared canons, the order, disposition, and goals of our narrative are not given. Thus, even at the level of a concrete legal case much is about ensuring that the system recognizes the world we are trying to assert, reproduce, and create. And this can certainly be enhanced by worldmaking and awareness of legal signs' relation to other semiospheres and the forms through which different media operate. Furthermore, the fact is that legal practice is increasingly governed by general concepts, constitutional values mediated by fundamental rights, and concerns towards the effects of norms and regulations [53]. In other words, it is becoming more forward-looking and legislative in nature. Thus, making an argument as to whether recognizing a foreign holographic will in Mexico City breaches the latter's public order; (ii) the right to life includes the right to quality of life and the enforcement of strict maximum noise levels in urban spaces; or, (iii) health emergencies' compulsory confinement policies breach individual freedom, entails in all cases engaging a complex process of cultural semiotics since the signifieds of the markers are deeply contested and, ultimately, justified by the kinds of worlds we envision, wish, and would like to live in. Embracing worldmaking in law is then a call to take responsibility for our common world.

Acknowledgements I thank Emilio Tejeda, Pablo Rapetti, Rodrigo Camarena, and Sara de Santis for excellent comments to a previous draft. I am also grateful for the feedback received at the Association of Law Teachers Virtual Conference, Aston University, April 15, 2021, where I presented an earlier version of this article. Two anonymous referees provided decisive criticism and enthusiasm that greatly benefited the article. All errors remain mine.

\section{References}

1. Aristodemou, Maria. 2014. Law, Psychoanalysis, Society: Taking the Unconscious Seriously. New York, Oxon: Routledge.

2. Barthes, Roland. 2007. L'Empire des Signes. Paris: Éditions du Seuil.

3. Barthes, Roland. 2013. Mythologies, trans. Richard Howard and Annette Lavers. New York, Hill and Wang.

4. Baudrillard, Jean. 1994. Simulacra and Simulation, trans Sheila Faria Glaser. Ann Arbor: The University of Michigan Press.

5. Bazzul, Jesse. 2015. Becoming a 'Mythologist': Barthes' Mythologies and Education. In: Peter Pericles Trifonas (eds) International Handbook of Semiotics. Springer, Dordrecht, pp. 1155-1168

6. Broekman, Jan M. and Larry Catá Backer. 2013. Signs, and Signs in Law. In Lawyers Making Meaning: The Semiotics of Law in Legal Education II, ed. Jan M. Broekman and Larry Catá Backer, 19-32. Dordrecht: Springer.

7. Carpenter, Stanford W. 2005. Truth Be Told: Authorship and the Creation of the Black Captain America. In Comics as Philosophy, ed. Jeff Mclaughlin, 46-62. Jackson: University Press of Mississippi. 
8. Csikszentmihalyi, Mihaly and Jacob W. Getzels. 2014. Discovery-Oriented Behavior and the Originality of Creative Products: A Study with Artists. In The Systems Model of Creativity-The Collected Works of Mihaly Csikszentmihalyi, 1-10. Dordrecht: Springer).

9. Cohn, Neil. 2013. The Visual Language of Comics: Introduction to the Structure and Cognition of Sequential Images. London, New York: Bloomsbury.

10. Culler, Jonathan. 1990. Framing the Sign: Criticism and Its Institutions. Oklahoma: Oklahoma University Press.

11. Douzinas, Costas. 2011. A Legal Phenomenology of Images. In Law and Art: Justice, Ethics and Aesthetics, ed. Oren Ben-Dor, 247-258. Abingdon: Routledge.

12. Douzinas, Costas, and Adam Gearey. 2005. Critical Jurisprudence: The Political Philosophy of Justice. Oxford: Hart Publishing.

13. Fitzpatrick, Peter. 1992. The Mythology of Modern Law. New York: Routledge, London.

14. Garon, Jon M. 2013. Legal Education in Disruption: The Headwinds and Tailwinds of Technology. Connecticut Law Review 45 (4): 1165-1233.

15. Giddens, Thomas, ed. 2020. Critical Directions in Comics Studies. Jackson: University Press of Mississippi.

16. Giddens, Thomas. 2019. On Comics and Legal Aesthetics: Multimodality and the Haunted Mask of Knowing. Oxford, New York: Routledge.

17. Glancey, Richard. 2015. I Am the Law Teacher! An Experiential Approach Using Judge Dredd to Teach Constitutional Law. In Graphic Justice: Intersections of Comics and Law, ed. Thomas Giddens, 54-70. Abingdon; New York: Routledge

18. Goodenough, Oliver R. 2013. Developing an E-Curriculum: Reflections on the Future of Legal Education and on the Importance of Digital Expertise. Chicago-Kent Law Review 88 (3): 845-878.

19. Goodman, Nelson. 1978. Ways of Worldmaking. Indianapolis: Hackett Publishing Company.

20. Goodrich, Peter. 1984. Law and Language: An Historical and Critical Introduction. Journal of Law \& Society 11 (2): 173-206.

21. Granat, Richard S., and Stephanie Kimbro. 2013. The Teaching of Law Practice Management and Technology in Law Schools: A New Paradigm. Chicago-Kent Law Review 88 (3): 757-782.

22. Gregory, Chase. 2012. In the Gutter: Comix Theory. Studies in Comics 3 (1): 107-128.

23. Groensteen, Thierry. 2007. The System of Comics, trans Bart Beaty and Nick Nguyen. Jackson: University Press of Mississipp.

24. Hague, Ian. 2014. Comics and the Senses: A Multisensory Approach to Comics and Graphic Novels. New York: Routledge.

25. Harris, Angela P., and Marjorie M. Shultz. 1993. “A(nother) Critique of Pure Reason”: Toward Civic Virtue in Legal Education. Stanford Law Review 45: 1773-1805.

26. WE Hornsby Jr. 2013. Gaming the System: Approaching 100\% Access to Legal Services Through Online Games. Chicago-Kent Law Review 88 (3): 917-944.

27. Hughes, Robert. 1996. The Fatal Shore. London: Harvill.

28. Jacobs, Dale. 2007. More than Words: Comics as a Means of Teaching Multiple Literacies. The English Journal 96 (3): 19-25.

29. Kennedy, Duncan. 1982. Legal Education and the Reproduction of Hierarchy. Journal of Legal Education 32: 591-615.

30. Kevelson, Roberta. 1988. The Law as a System of Signs. New York, London: Springer.

31. Klink, Bart van and Bald, Vries de. 2013. Skeptical Legal Education: How to Develop a Critical Attitude? Law and Method 3 (2): 37-52.

32. Krygier, Martin. 1986. Law as Tradition. Law and Philosophy 5 (2): 237-262.

33. Lotman, Juri. 2005. On the Semiosphere. Sign Systems Studies 33 (1): 205-229.

34. Luhmann, Niklas. 2008. Law as a Social System, trans Klaus Ziegert. Oxford, New York: Oxford University Press.

35. Manderson, Desmond. 2019. Danse Macabre: Temporalities of Law in the Visual Arts. London: Cambridge University Press.

36. Manderson, Desmond. 2000. Songs without Music: Aesthetic Dimensions of Law and Justice. Berkeley: University of California Press.

37. McCloud, Scott. 1994. Understanding Comics - The Invisible Art. New York: Harper Perennial.

38. Mikkonen, Kai. 2017. The Narratology of Comic Art. New York, London: Routledge.

39. Modiri, Joel. 2014. The Crises in Legal Education. Acta Academica 46 (3): 1-24.

40. Patterson, Dennis. 1996. Law and Truth. New York: Oxford University Press. 
41. Pistone, Michele. 2015. Law Schools and Technology: Where We Are and Where We Are Heading. Journal of Legal Education 64 (4): 586-604.

42. Pistone, Michele R. and Michael B. Horn. 2016. Disrupting Law School: How Disruptive Innovation Will Revolutionize the Legal World. Clayton Christensen Institute for Disruptive Innovation. https://www.christenseninstitute.org/publications/disrupting-law-school/ Accessed 25 April 2021.

43. Romero, Luis Gomez, and Ian Dahlman. 2012. Introduction - Justice Framed: Law in Comics and Graphic Novels. Law Text Culture 16 (1/2): 3-32.

44. Sedda, Franciscu. 2015. Semiotics of Culture(s): Basic Questions and Concepts. In International Handbook of Semiotics, ed. Peter Pericles Trifonas, 675-696. Dordrecht: Springer.

45. Smith, Marcus. 2020. Integrating Technology in Contemporary Legal Education. The Law Teacher 54 (2): 209-221.

46. Sokhi-Bulley, Bal. 2013. Alternative Methodologies: Learning Critique as a Skill. Law and Method 3 (2): 6-23.

47. Staples, Fiona, and Brian K. Vaughan. 2017. Saga Book Two. Portland: Image Comics.

48. Stern, Simon, Maksymilian Del Mar, and Bernadette Meyler, eds. 2020. Handbook of Law and Humanities. New York: Oxford University Press.

49. Vattimo, Gianni. 2010. Adiós a la Verdad, trans. Editorial Gedisa, Barcelona: Maria Teresa d'Meza.

50. Vaughan, Brian K., and Fiona Staples. 2019. Saga Book Three. Portland: Image Comics.

51. Vaughan, Brian K., and Fiona Staples. 2014. Saga Book One. Berkeley: Image Comics.

52. Vilaça, Guilherme Vasconcelos. 2021. Worlds, Legal Subject, Legal Consciousness, and Normativity in Walser's 'The Robber' and Kadare's 'Broken April' (on file with author)

53. Vilaça, Guilherme Vasconcelos. 2015. Why Teach Legal Theory Today? German Law Journal 16 (4): 781-820.

54. Ward, Ian. 1995. Law and Literature: Possibilities and Perspectives. New York, Melbourne: Cambridge University Press.

55. Watson, Burton. 2013. The Complete Works of Zhuangzi. New York: Columbia University Press.

56. Watt, Gary. 2013. Dress, Law and Naked Truth: A Cultural Study of Fashion and Form. London: Bloomsbury.

57. White, James Boyd. 1985. Doctrine in a Vacuum: Reflections on What a Law School Ought (and Ought Not) to Be. University of Michigan Journal of Law Reform 18 (2): 251-266.

58. Wood, Amy Louise. 2005. Lynching Photography and the Visual Reproduction of White Supremacy. American Nineteenth Century History 6 (3): 373-399.

Publisher's Note Springer Nature remains neutral with regard to jurisdictional claims in published maps and institutional affiliations. 